\title{
Analisis Tahapan dalam Belajar Konsep
}

\author{
Noviani Tarigan ${ }^{\left.{ }^{*}\right)}$ Neviyarni $^{2}$ \\ ${ }^{12}$ Magister Bimbingan dan Konseling Universitas Negeri Padang, Sumatera Barat , Indonesia \\ *Corresponding author, e-mail: novianitarigan@gmail.com neviyarni.suhaili911@gmail.com
}

Received January 12th , 2021; Revised Month February 1st, 2021;

Accepted March 15, 2021; Published Online March 20, 2021

\section{Conflict of Interest Disclosures:}

The authors declare that they have no significant competing financial, professional or personal interests that might have influenced the performance or presentation of the work described in this manuscript.

\begin{abstract}
Concept learning refers to any activity in which learners must classify two or more somewhat different events or objects into one category, concept learning includes learning to make general responses to a group of stimuli that have some of the same features or properties. Concept refers to a set of features or attributes of one or more general properties connected by a rule. Learning concepts on the other hand includes learning a single response to two or more stimuli which is a comparison between stimulus and response. Concept learning requires that learners come to respond to features that are relevant to the concept and ignore features that are not relevant in classifying events.
\end{abstract}

\section{Keywords: Concept learning}

Indonesian Abstract: Pembelajaran konsep mengacu pada setiap aktivitas di mana peserta didik harus mengklasifikasikan dua atau lebih peristiwa atau objek yang agak berbeda ke dalam satu kategori, pembelajaran konsep mencakup pembelajaran untuk membuat tanggapan umum terhadap sekelompok rangsangan yang memiliki beberapa fitur atau sifat yang sama. Konsep mengacu pada sekumpulan fitur atau atribut dari satu atau lebih properti umum yang dihubungkan oleh suatu aturan. Konsep pembelajaran di sisi lain mencakup pembelajaran respons tunggal terhadap dua atau lebih rangsangan yang merupakan perbandingan antara rangsangan dan tanggapan. Pembelajaran konsep mengharuskan peserta didik datang untuk menanggapi fitur yang relevan dengan konsep dan mengabaikan fitur yang tidak relevan dalam mengklasifikasikan peristiwa.

Kata kunci: Pembelajaran konsep

How to Cite: Noviani Tarigan, Neviyarni. 2021. Analisis Tahapan dalam Belajar Konsep. JIBK Undiksha, 12 (1): pp.84-89. DOI: http://dx.doi.org/10.23887/xxxx

\section{Pendahuluan}

Pada saat ini penting bagi kita untuk belajar konsep tentang suatu hal. Maksud dari kata konsep adalah bagian-bagian yang diberikan oleh stimulus atau rangsangan yang terdapat pada lingkungan kita. Konsep dalam struktur kognitif individu adalah hasil dari pengalaman yang ia peroleh. Oleh karena itu, konsep yang dimiliki seseorang merupakan hasil dari proses belajar dimana proses hasil dari belajar ini menjadi suatu pondasi (building blocks) di dalam struktur berpikir seseorang. Konsep inilah yang dijadikan dasar oleh seseorang dalam memecahkan masalah, mengetahui aturan-aturan yang relevan, dan hal lain yang ada keterkaitannya dengan apa yang harus dilakukan oleh individu. 
Menurut salah satu ahli, konsep adalah suatu abstraksi yang mewakili suatu kelas objek, kejadian, kegiatan, atau hubungan yang mempunyai atribut yang sama (Croser, 1984).Pada pembahasan kali ini kita akan membahas tentang hakikat belajar konsep, belajar konsep, generalisasi, dan diskriminasinya. Kemudian kajian tentang belajar konsep, faktor-faktor yang mempengaruhi belajar konsep, teori-teori belajar konsep, dan terakhir prinsip praktis belajar konsep.

\section{Metode}

Penelitian ini membahas tentang analisis tahapan dalam belajar konsep, jenis metode penelitian ini adalah analisis kajian pustaka (literatur research) artikel ini akan memaparkan analisis jurnal ilmiah yang relevan dengan pembahasan yang sudah dipilih, adapun tahap- tahap dalam metode penelitian ini adalah (1) memilih artikel, (2) mengumpulkan data awal, (3) tantangan dari topik, (4) mengumpulkan data pendukung, (5) menghasilkan kesimpulan dan rekomendasi online.

\section{Hasil dan Pembahasan \\ Hakikat Belajar Konsep}

Belajar konsep berguna untuk membantu dalam berbagai hal yang mendetail dan tidak terbatas dari suatu keadaan dan juga memberikan tindakan pada suatu kejadian yang mempunyai sifat sama yang merupakan bagian dari kelompok tertentu. Contoh, jika anak-anak mempelajari tentang kucing, mereka hanya tahu kucing yang ada di rumah mereka saja, mereka tidak akan mengembangkan konsep tentang kucing tersebut. Tapi mereka harus mampu menggunakan istilah ini pada sejumlah contoh-contoh spesifik dengan cara akurat yang masuk akal, barulah dikatakan mereka mempelajari konsep.

Berdasarkan hal tersebut, kita dapat melihat begitu pentingnya pendidikan formal, dimana salah satu tujuannya adalah mengajarkan konsep-konsep dasar untuk membantu manusia agar berfungsi efektif dalam kehidupan sehari-hari bermasyarakat dan mengajarkan bahwa konsep-konsep tersebut dapat berubah, diperbaharui, dan diperbaiki berdasarkan ilmu dan pengalaman baru.

Menurut Ellis, H.C (1978: 133) pembelajaran konsep adalah membuat manusia mampu merespon bentuk-bentuk yang relevan (berhubungan) dengan konsep tersebut dan tidak menghiraukan (ignore) bentukbentuk yang tidak relevan dengan kategori/pengelompokkannya. Dengan kata lain dari banyak kata, bisa disempitkan lagi kepada hal yang lebih spesifik, contohnya: Binatang, kira-kira apa konseptual dari binatang itu, misalnya, "rusa", berkaki empat, punya ekor, tanduk, warna kulitnya kecoklatan, suka makan rumput, dan sebagainya.

Pembelajaran konsep mengacu kepada semua kegiatan dimana si pelajar harus belajar mengelompokkan dua atau lebih objek atau peristiwa yang agak berbeda ke dalam satu kategori. Pembelajaran konsep mencakup belajar membuat respon yang sama atau berkelompok terhadap sekelompok stimulus yang memiliki bentuk atau sifat yang sama. Secara umum konsep mengacu kepada seperangkat bentuk atau atribut yang memiliki satu atau lebih properti secara bersama yang dikaitkan dengan satu aturan.

\section{Belajar Konsep, Generalisasi, dan Diskriminasi}

Ellis, H.C (1978: 135) mengatakan pembelajaran konsep dipandang sebagai sebuah kombinasi dari perbedaan antara kelompok-kelompok kejadian dengan generalisasi dalam kelompok-kelompok kejadian. Contoh: bagaimana seseorang mengajarkan konsep tentang lingkaran, segitiga, dan persegi. Anak-anak diperlihatkan beberapa contoh dari masing-masing konsep yang bervariasi bentuk, ukuran, dan warna. Jika mereka mampu membedakan ketiga bentuk tadi dengan benar, berarti mereka telah mengetahui apa itu konsep.

Menurut Syah, M (2011: 30) konsep atau pengertian adalah satuan arti yang mewakili sejumlah objek yang mempunyai ciri-ciri yang sama. Seseorang yang mempunyai konsep dapat mengadakan proses pemisahan terhadap suatu objek yang dihadapi, sehingga objek ditempatkan pada golongan tertentu. Objek tersebut didatangkan dalam kesadaran seseorang dengan diwakili oleh mental tak berperaga. Konsep tersebut dapat dilambangkan dalam bentuk suatu kata (lambang bahasa). Dengan demikian, belajar konsep 
adalah berpikir dalam konsep dan belajar pengertian. Tingkat pertama adalah tingkat pengetahuan yaitu belajar reseptif (penerimaan).

Belajar konsep generalisasi dan deskriminasi berakar dari teori yang dikembangkan oleh Ivan Pavlov yaitu teori clasical conditioning. Maksud dari kata klasikal yang dipakai adalah untuk menghargai karya Pavlov yang mana teorinya tersebut lebih dulu dari pada terori conditioning yang lainnya.

\section{Kajian tentang Belajar Konsep}

Ada beberapa kajian tentang belajar konsep menurut Ellis, H.C (1978: 136) yaitu:

\section{Features of Concept Learning Tasks (Ciri-ciri Belajar Konsep)}

Dalam belajar konsep memerlukan suatu stimulus atau yang disebut dengan rangsangan, kemudian juga respon atau tanggapan dan juga umpan balik kepada leaener atau seorang pelatih. Stimulus meliputi contoh positif dan contoh negatif, respon dapat memakai cara yang paling sederhana sampai kepada yang agak rumit, dan umpan balik diberikan sebagai pembetulan terhadap respon. Contoh : bagaimana konsep cara makan yang baik, yaitu cuci tangan dahulu, duduk, tidak bersuara, dan sebagainya (stimulus positif), sedangkan konsep bagaimana cara makan yang tidak baik, justru sebaliknya (stimulus negatif).

\section{Basic Paradigms (Paradigma Dasar)}

Ada dua prosedur dasar dalam investigasi perilaku konseptual, yaitu :

a) Paradigma Penerimaan (Reception Paradigm)

b) Paradigma Seleksi (Selection Paragdigm), subjek dihadirkan keseluruhan set dari Attributes and Rules (Atribut dan Aturan)

c) Classification of Conceptual Rules (Klasifikasi dari Aturan Konseptual)

d) Ada lima macam dasar aturan yang digunakan dalam studi tentang belajar konsep, yaitu :

Aturan Affirmation, menegaskan konsep secara sederhana dengan pemberian atribut yang sederhana, contoh konsep tentang "kuning", semua objek yang kuning berbagai bentuk dan ukuran, adalah contoh dari konsep "kuning".

1) Aturan Conjunction, yaitu menjelaskan konsep dengan menggabungkan dua atribut. Contoh, "Ember merah" adalah sebuah objek yang berbentuk ember dan berwarna merah. Jadi ember merah adalah konsep konjungtif.

2) Aturan Disjunction, yaitu menjelaskan konsep dengan dua atribut dengan menggunakan hubungan dan/atau dari keduanya. Contoh, "Pemilih yang memenuhi syarat" adalah warga yang berusia 17 tahun dan atau sudah menikah.

3) Aturan Conditional, dimana sesuatu berlaku sebagai sebuah atribut yang relevan tergantung pada adanya atribut yang lain. Contoh, jika sebuah objek berwarna hitam, maka ia harus berbentuk segiempat untuk menjadi contoh bagi suatu konsep, misalnya meja.

4) Aturan Biconditional, mengilustrasikan contoh menggunakan dua atribut dengan hubungan jika dan hanya jika. Contoh, sebuah AC dihidupkan jika dan hanya jika hari panas.

\section{Faktor-faktor yang Mempengaruhi Belajar Konsep}

Ellis, H.C (1978: 140) mengemukakan ada beberapa faktor yang mempengaruhi belajar konsep, sebagai berikut:

1. Positive and Negative Instances (Kejadian positif dan negatif)

Manusia lebih cepat belajar dari kejadian positif dibandingkan kejadian negatif, hal ini disebabkan mungkin kejadian negatif itu lebih sedikit memberikan informasi dibandingkan dengan kejadian positif.

2. Relevant and Irrelevant Attributes (Atribut relevan dan tidak relevan)

Apabila suatu atribut yang tidak relevan semakin bertambah dalam tugas konseptual, maka akan semakin sukar tugas tersebut. Dan begitu juga sebaliknya banyak jumlah atribut relevan maka akan mudah belajar konsep. 
3. Stimulus Salience and Abstractness-Concreteness (Stimulus Mencolok dan KeabstrakanKekonkritan).

Tanda-tanda yang mencolok dan tersendiri yang relevan akan mempermudah untuk belajar konsep, contohnya, anak-anak lebih mudah mempelajari konsep warna dibandingkan konsep bentuk.

4. Feedback and Temporal Factors (Umpan balik dan Faktor Temporal/Sementara).

Umpan balik dalam bentuk respon menunjukkan apakah benar atau tidak menyediakan pelajar dengan informasi tentang kebenaran tanggapannya. Umpan balik juga dapat berfungsi membimbing tanggapan berikutnya dalam tugas konseptual.

5. Conceptual Rules (Aturan-aturan Konseptual).

Agar memberikan kemudahan dalam pembelajaran konsep dapat dilakukan dengan cara menggabungkan aturan konseptual tersebut. Konsep yang menggunakan aturan konjungsi lebih gampang dipelajari dari konsep dengan aturan kondisional. Sehingga sebuah konsep dapat dijelaskan dengan aturan pemberian atribut.

6. Memory and Intelligence (Ingatan dan Intelegensi).

Hal yang mempengaruhi dalam kemudahan pembelajaran konsep adalah memori dan kecerdasan seseorang. Seseorang tersebut harus memiliki ingatan yang baik untuk mengingat informasi yang berhubungan dengan konsep yang dipelajari, maka semakin cerdas seseorang memecahkan tugas konseptual, semakin cepat ia mempelajari konsep.

\section{Teori-teori Belajar Konsep}

1. Teori Asosiasi $\mathrm{S}-\mathrm{R}$

Solso, Robert. L (2008: 403) mengemukakan bahwa teori yang tertua dan paling berpengaruh dalam pembentukan konsep adalah prinsip asosiasi dan juga diketahui sebagai asosianisme. Asosiasi ini menjelaskan bahwa pembelajaran konsep adalah hasil dari sebuah penguatan (hadiah) dan non penguatan (hukuman).

\section{Teori Pengujian Hipotesis}

Teori pengujian hipotesis dari pembelajaran konsep menekankan manusia sebagai orang yang belajar lebih aktif dalam memilih dan menguji solusi-solusi yang memungkinkan dilakukan untuk pemecahan masalah. Lebih mengutamakan penyelesaian hipotesis dari pengambilan keputusan. Terdapat dua cara, yaitu cara konservatif focusing dan cara focus gambling.

\section{Teori Pengolahan Informasi}

Teori ini menekankan pada ciri pengolahan informasi manusia dalam belajar konsep. Teori ini menilai belajar konsep sebagai suatu urutan proses pengambilan keputusan oleh seorang pelajar.

Robert (2008) menyatakan, teori yang tertua dan paling berpengaruh dalam pembentukan konsep adalah prinsip asosiasi juga diketahui sebagai asosiasisme. Dalam format ringkas, prinsip memegang ikatan yang akan yang akan terbentuk di antara kejadian (atau objek) setiap saat dimunculkan bersama kembali. Suatu pengutan dengan memberikan sebuah hadiah dapat memfasilitasi bentuk dari ikatan. Jadi prinsip asosiasi menjelaskan pembelajaran konsep adalah hasil dari:

a) Menguatkan pasangan tepat dari sebuah stimulus (misalnya kotak merah dengan respon yang mengidentifikasikannya sebagai sebuah konsep.

b) Nonpenguatan (bentuk hukuman) pasangan yang tidak tepat dari sebuah stimulus (contohnya lingkaran merah) dengan respons untuk mengidentifikasikannya sebagai konsep. 


\section{Prinsip-Prinsip Praktis Belajar Konsep}

Prinsip-prinsip praktis dalam belajar konsep adalah:

a. Dalam belajar konsep kita harus memikirkan contoh-contoh baru untuk konsep tersebut. Kita harus kreatif memberikan contoh tambahan selain dari contoh-contoh yang telah disajikan.

b. Kita harus menggunakan contoh keduanya, baik contoh positif maupun contoh negatif (positive and negative instance).

c. Untuk memantapkan konsep, kita harus menggunakan contoh-contoh yang bervariasi. Selanjutnya berikan variasi yang bermacam-macam sehingga proses belajar memproleh suatu konsep yang optimal

d. Kita harus memberikan penekanan pada bentuk-bentuk yang relevan, sehingga tidak terjadi kesalahfahaman.

Menurut Ellis, H.C (1978: 151) Beberapa prinsip-prinsip praktis belajar konsep, sebagai berikut:

a. Think of New Examples of Concept (Memikirkan Contoh-contoh Baru untuk Konsep)

Agar konsep sepenuhnya dipahami dan dimengerti, penting untuk memikirkan contoh-contoh tambahan selain yang disajikan oleh instruktur, sehingga memikirkan contoh baru tidak hanya mempertajam, memurnikan dan memperkaya konsep tetapi juga memberikan praktek dalam proses pencarian informasi penting.

\section{b. Use both Positive and Negative Instances (Menggunakan Kedua Contoh Positif dan Negatif)}

Selain memikirkan contoh-contoh baru, kita juga menggunakan kejadian/contoh-contoh positif dan negatif agar pembelajaran konsep lebih dipahami dan dimengerti, harus mampu membedakan objek atau peristiwa mana yang termasuk contoh konsep yang positif, dan mana yang tidak termasuk contoh sebuah konsep negatif.

\section{c. Use a Variety of Example (Menggunakan Berbagai Contoh)}

Bagian-bagian sebelumnya secara implisit menekankan pentingnya berbagai contoh pada pembelajaran konsep. Kita harus memilih variasi yang cukup banyak sehingga proses pembelajaran akan mencapai pemahaman konsep yang optimal. Dengan demikian menggunakan contoh-contoh yang bervariasi, untuk mempermudah dalam belajar konsep.

\section{d. Highlight Relevant Features (Fitur Pokok yang Relevan)}

Tugas utama adalah menekankan fitur yang relevan dari konsep, tujuannya agar tidak terjadi kesalahpahaman.

\section{Simpulan}

Belajar adalah suatu proses interaksi yang dilakukan seseorang terhadap semua situasi yang ada. Sedangkan konsep merupakan suatu abstraksi mental dari pengalaman responsif terhadap stimulus. Seseorang tersebut mendapat suatu kosep melalui formasi konsep dan asimilasi konsep. Ada empat tingkat pencapaian konsep yaitu tingkat konkret, tingkat klasifikatori, tingkat identitas, dan tingkat formal. Jadi belajar konsep adalah suatu aktivitas dalam pembelajaran dimana peserta didik harus belajar untuk mengelompokkan atau mengklasifikasikan beberapa objek yang berbeda dalam satu kategori. Sehigga dapat disimpulkan bahwa pembelajran konsep ialah belajar dalam membuat suatu tanggapan umum kepada sekelompok stimulus yang memiliki beberapa fitur atau sifat yang sama.

Ada beberapa kajian tentang belajar konsep yaitu, features of concept learning tasks (ciri-ciri belajar konsep), konsep ini menjelaskan bahwa belajar konsep memerlukan suatu stimulus atau yang disebut dengan rangsangan, kemudian juga respon atau tanggapan dan juga umpan balik kepada leaener atau seorang pelatih. Basic paradigms (paradigma dasar) yang dimana belajar konsep memrlukan paradigma dasar dan paradigma seleksi. Kemudian attributes and rules (atribut dan aturan) serta classification of conceptual rules (klasifikasi dari aturan konseptual). 
Factor-faktor yang mempengaruhi belajar konsep yakni, positive and negative instances (kejadian positif dan negatif), relevant and irrelevant attributes (atribut relevan dan tidak relevan), stimulus salience and abstractness-concreteness (stimulus mencolok dan keabstrakan-kekonkritan), feedback and temporal factors (umpan balik dan faktor temporal/sementara), conceptual rules (aturan-aturan konseptual), dan memory and intelligence (ingatan dan intelegensi).

Selain itu, di dalam belajar konsep ada teori-teori yang menjelaskan bagaimana keberhasilan pembelajaran konsep. Teori tersebut antara lain, teori asosiasi $s-r$, teori pengujian hipotesis, dan teori pengolahan informasi. Pada Prisip dalam belajar konsep juga harus memperhatikan beberapa hal yakni, memikirkan contoh baru untuk konsep, menggunakan kedua contoh positif dan negatif, menggunakan berbagai contoh, fitur pokok yang relevan.

\section{Ucapan Terimakasih}

Puji syukur atas kehadirat Tuhan Yang Maha Esa yang telah memberi nikmat dan karunianya sehingga saya dapat menyelesaikan tugas ini hingga waktu yang telah ditentukan. Tanpa pertolongan-Nya tugas ini tidak akan terselesaikan dengan baik. Ucapan terima kasih saya sampaikan kepada dosen pembimbing mata kuliah Psikologi Belajar ibu Prof. Dr. Neviyarni S., M.S dengan bimbingan dan arahannya serta kesabarannya sehingga tugas individu dengan materi Belajar Konsep ini dapat saya selesaikan.

Dalam penyusunan artikel ini tidak luput dari salah, maka dari itu saya mohon koreksinya untuk perbaikan kedepannya, sehingga dapat membuat artikel yang lebih baik lagi.

\section{Refrensi}

Henry C. Ellis, 1978. Fundamentals of Human Learning, Memory, and Cognition, USA: Brown Company Publishers.

Muhibbin Syah, 2008. Psikologi Pendidikan dengan Pendekatan Baru, Bandung: Remaja Rosdakarya

Tohirin, 2008. Psikologi Pembelajaran Pendidikan Agama Islam, Jakarta: Rajawali Pers

Slavin, Robert. E. 2011. Psikologi Pendidikan Teori dan Praktik. Jakarta: PT Indeks.

Solso, Robert, L. 2008. Psikologi Kognitif. Jakarta: Erlangga.

Article Information (Supplementary)

\section{Conflict of Interest Disclosures:}

The authors declare that they have no significant competing financial, professional or personal interests that might have influenced the performance or presentation of the work described in this manuscript.

Copyrights Holder: < Noviani Tarigan $><2021>$

First Publication Right: JIBK Undiksha

https://doi.org/10.xxxx/xxxxx

Open Access Article | CC-BY Creative Commons Attribution 4.0 International License.

Word Count: 